\title{
Comparison of benefit from L-dopa in Parkinsonism with increase of amine metabolites in the CSF
}

\author{
R. B. GODWIN-AUSTEN', B. D. KANTAMANENI, AND G. CURZON \\ From the Institute of Neurology, The National Hospital, Queen Square, London
}

SUMMARY Homovanillic acid (HVA) and 5-hydroxy indole acetic acid (5-HIAA) concentrations have been estimated in the cerebrospinal fluid (CSF) of 16 and 18 patients respectively with Parkinsonism both before and during treatment with L-dopa. The rise of HVA correlated with dose of L-dopa. An increase of HVA concentration to less than $0.10 \mu \mathrm{g} / \mathrm{ml}$. was associated with little or no clinical improvement. The five patients with the greatest increase of HVA concentration/g L-dopa showed little or no improvement from treatment and four of these patients had normal pre-treatment HVA and 5-HIAA. In those patients who responded well to L-dopa the CSF HVA/g L-dopa was intermediate between that of these two groups. It is suggested that change in HVA content of CSF during L-dopa treatment might be of value in the prediction of response to L-dopa.

While L-dopa has been shown to have a striking therapeutic effect in Parkinsonism, by no means all patients show improvement (Cotzias, Papavasiliou, and Gellene, 1969; Yahr, Duvoisin, Schear, Barrett, and Hoehn, 1969; Mawdsley, 1970). Furthermore, improvement after L-dopa treatment may take many weeks or months to become maximal (Yahr et al., 1969; Mawdsley, 1970; Peaston and Bianchine, 1970), so that a prolonged trial of therapy may be needed to assess whether benefit will result from it. In general, akinesia and rigidity respond better to Ldopa than does tremor (Calne, Speirs, Stern, and Laurence, 1969; Cotzias et al., 1969; GodwinAusten, Tomlinson, Frears, and Kok, 1969). However, at present, it cannot be predicted which of the patients with akinesia and rigidity are likely to improve. Thus, no relationship is apparent between therapeutic response and age, sex, or duration or aetiology of disease. While some relationship between maximum tolerated dose and likelihood of improvement would seem reasonable and it has been reported that severely handicapped patients are less likely to benefit, a method of predicting benefit from treatment would be of great value.

Administration of L-dopa causes an increase in the cerebrospinal fluid (CSF) of the dopamine metabo-

${ }^{1}$ Reprint requests to R.B.G-A, Department of Neurology, Derbyshire Royal Infirmary, Derby. lite homovanillic acid (HVA) (Guldberg and Yates, 1968; Persson and Roos, 1968; Weiner, Harrison, and Klawans, 1969). The increase was found to be significantly correlated with the dose of L-dopa (Curzon, Godwin-Austen, Tomlinson, and Kantamaneni, 1970) in a study of seven patients. It was found that patients with the lowest HVA in the CSF while on L-dopa showed no benefit. More surprisingly, the patient with the highest HVA while on the drug showed only moderate improvement. These findings, though on a small group of subjects, suggest that an increase of HVA to an intermediate level on L-dopa treatment might be characteristic of the patients who showed significant benefit. During a trial of L-dopa in a larger group of patients with Parkinsonism we have been able to strengthen the above suggestion and to show that the subjects who attained the greatest increase of HVA in the CSF had a higher mean HVA concentration before treatment than the other subjects on the same dose of L-dopa.

\section{METHODS}

Eighteen patients with Parkinsonism were investigated in a trial of long-term treatment with L-dopa. Patients were taken from the diagnostic index of the National Hospital, Queen Square, London, in a random manner except for the following restrictions. Equal numbers of patients less than 65 and more than 65 years old were included and two patients were specifically selected who were considered to 
be suffering from arteriosclerotic Parkinsonism. This diagnosis was agreed by two neurologists on the basis of sudden onset and stepwise progression of symptoms, evidence of generalized arteriosclerosis and clinical features regarded as typical of this condition such as 'marche à petits pas', pyramidal as well as extra-pyramidal signs, pseudobulbar palsy, and slightness or absence of tremor. Subjects were excluded if they showed a significant physical or mental disability not attributable to their Parkinsonism and likely to interfere with assessment of their disability. Patients were also excluded who were on monoamine oxidase inhibitors, had previously been treated with L-dopa, gave a history of cardiac, hepatic or renal disease, or had suffered from any blood dyscrasia.

Patients were initially interviewed in the out-patient department, the purpose of the trial explained to them and their full cooperation achieved. They were then examined and an assessment of their Parkinsonism made as previously described (Godwin-Austen et al., 1969). Upon subsequent admission to hospital, a second assessment was made and full investigations including lumbar puncture carried out. Treatment with L-dopa was then started and increased progressively to a maximum of $\mathbf{8 g}$ daily, or until side-effects occurred. L-dopa was given in three or four divided doses daily after meals except for one patient who was given two divided doses daily. Other treatment was left unchanged throughout. Nausea was treated with concurrent administration of promethazine theoclate (Avomine) or metoclopramide (Maxolon). About two weeks after starting treatment a second lumbar puncture was performed within one to four hours of an oral dose of L-dopa. The time course of 5-hydroxy indole acetic acid (5-HIAA) increase in lumbar CSF after oral tryptophan (Eccleston, Ashcroft, Crawford, Stanton, Wood, and McTurk, 1970) suggests that the HVA concentration in CSF of subjects on divided doses of L-dopa is not critically dependent on time of puncture. HVA was determined as previously described (Eccleston et al., 1970) and 5-HIAA, the major metabolite of 5-hydroxytryptamine (5-HT), by the cysteine-phthalaldehyde method (Korf and Valkenburgh-Sikkema, 1969). Determinations were also done on a control group of patients submitted to lumbar puncture during neurological investigation. Patients showing evidence of extrapyramidal disease or spinal block or with high CSF protein or under phenothiazine treatment were excluded.

\section{RESULTS}

HVA and 5-HIAA levels in the CSF before L-dopa treatment are shown in Fig. 1. The mean HVA content of the CSFs of 16 subjects with Parkinsonism was $0.016 \pm 0.019 \mu \mathrm{g} / \mathrm{ml}$., which was significantly different $(\overline{\mathrm{P}}<0.01)$ from $0.045 \pm 0.016 \mu \mathrm{g} / \mathrm{ml}$. found for a group of nine assorted subjects without Parkinsonism. Though low HVA was characteristic of the Parkinsonism group as a whole, three of the patients, A, B, and C, had CSF HVA contents of $0.063,0.026$, and $0.056 \mu \mathrm{g} / \mathrm{ml}$. respectively, which are similar to values found for the control group. Two of these latter patients, $A$ and $B$, were men aged

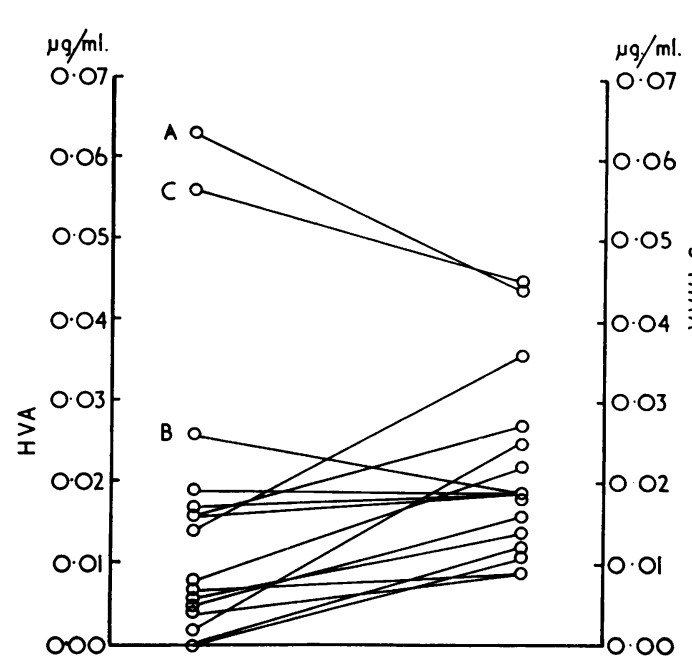

FIG. 1. HVA and 5-HIAA in lumbar CSF of patients wit Parkinsonism before $\mathrm{L}$-dopa treatment.

65 and 79 respectively with arteriosclerotic Park sonism, while the third patient, $\mathrm{C}$, was a woman ages 71 with moderate arteriosclerosis and tremor as ber only Parkinsonism symptom. The CSF 5-HIAA of the Parkinsonism group was $0.021 \pm 0.011 \mu \mathrm{g} / \mathrm{f}$ 居 for 18 subjects, which was not significantly different from $0.027 \pm 0.010(P>0.05)$ for nine con patients. A, B, and C had CSF 5-HIAA $=0.074$ 0.019 , and $0.045 \mu \mathrm{g} / \mathrm{ml}$. respectively (see, howevero Table).

Figure 2 shows the increase of HVA in the CSF during L-dopa treatment. There was a wide sprea行 of values but in agreement with earlier work (Curzon et al., 1970) significant correlations between $\overrightarrow{5}$ increase of HVA and L-dopa intake occurred (Table) $\Xi$ Those subjects with an increase of HVA of $<0.1 \mathrm{~g}$ $\mu \mathrm{g} / \mathrm{ml}$. (the HVA concentration attained also being. $<0.010 \mu \mathrm{g} / \mathrm{ml}$.) showed no more than slighf improvement. However, though all patients who improved considerably had a greater increase of HVA, four of the five patients with the greatese. increase of HVA/g L-dopa administered showed no improvement and the fifth only improved slightly Three of these were the patients A, B, and C referred to above, who, unlike most of the other subjects with? Parkinsonism symptoms, did not have low pres treatment HVA.

The other subjects in this group are indicated in Fig. 2 by $D$ and E. Patient $D$ was aged 72 and showed evidence of moderate arteriosclerosis. She had mild idiopathic paralysis agitans with unilateraf tremor as her major symptom. Her pre-treatment HVA 
TAB LE

CSF AMINE METABOLITES BEFORE AND AFTER L-DOPA TREATMENT OF PATIENTS WITH PARKINSONISM

\begin{tabular}{|c|c|c|c|c|c|}
\hline \multirow[t]{2}{*}{ Subjects } & \multicolumn{3}{|c|}{ Amine metabolites in CSF before $\mathrm{L}$-dopa treatment } & \multirow{2}{*}{$\begin{array}{l}\text { Regression equation } \\
\text { relating increase of CSF } \\
H V A(y) \text { to L-dopa/day }(x)\end{array}$} & \multirow[t]{2}{*}{ Improvement on $\mathrm{L}$-dopa } \\
\hline & $H V A \mu g / m l$. & 5-HIAA $\mu \mathrm{g} / \mathrm{ml}$. & & & \\
\hline \multirow[t]{2}{*}{ Patients $A-E$} & \multirow[t]{2}{*}{$0.032 \pm 0.027(5)$} & $0.029 \pm 0.015(5) ?$ & & \multirow{5}{*}{$\begin{array}{l}y=0.187 x+0.005(5) \\
\text { Correlation }=1.000 \\
\text { (significant at better than } \\
1 \% \text { level) } \\
y=0.0342 x+0.030(10) \\
\text { Correlation }=0.668 \\
\text { (significant at better than } \\
5 \% \text { level) }\end{array}$} & \\
\hline & & $P<0.05$ & NS & & Negligible \\
\hline \multirow[t]{2}{*}{$\begin{array}{l}\text { Other patients with } \\
\text { Parkinsonism }\end{array}$} & \multirow[t]{2}{*}{$0.009 \pm 0.007(11)\}$} & $0.018 \pm 0.007(13)$ & & & $\begin{array}{l}\text { Definite in subjects whose } \\
\text { CSF HVA increased to }\end{array}$ \\
\hline & & $\mathrm{P}<0.001$ & $P<0.02$ & & $>0 \cdot 100 \mu \mathrm{g} / \mathrm{ml}$ \\
\hline $\begin{array}{l}\text { Neurological patients } \\
\text { without Parkinsonism }\end{array}$ & $0.045 \pm 0.016(9)]$ & $0.027 \pm 0.010(9)\}$ & & & \\
\hline
\end{tabular}

Numbers of subjects are indicated in parentheses.

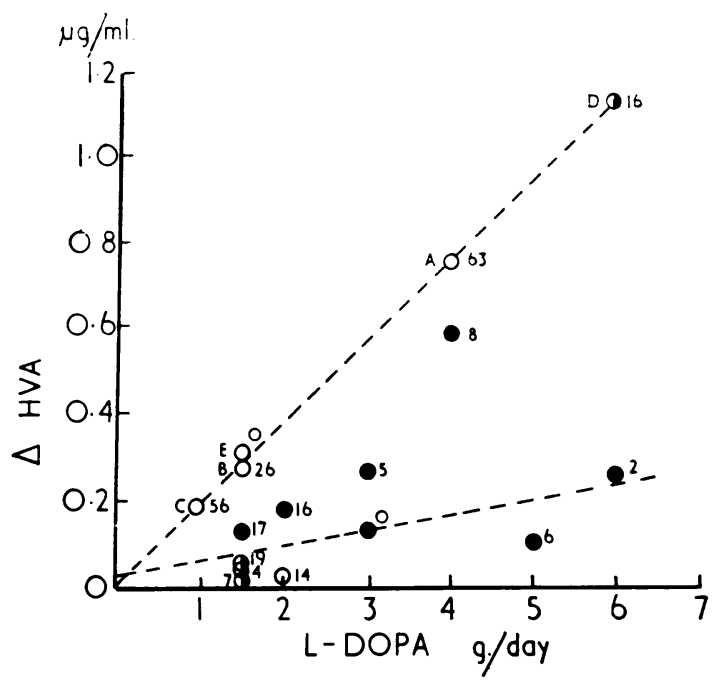

FIG. 2. Increase of $H V A$ in lumbar CSF during L-dopa treatment $\bigcirc$, no improvement; $($, slight improvement; - considerable improvement. Numbers against points are nanograms/ml. HVA in CSF before treatment.

was $0.016 \mu \mathrm{g} / \mathrm{ml}$. On treatment with $6 \mathrm{~g}$ L-dopa daily clinical improvement was only slight. Patient $\mathrm{E}$ was aged 79 and like patient $D$ showed evidence of generalized arteriosclerosis. His Parkinsonism was probably 'idiopathic' and not attributable to his arteriosclerosis. During treatment with $1.0 \mathrm{~g}$ L-dopa daily there was no definite improvement. Before treatment HVA was not detectable in his CSF. The lack of clinical effect but large biochemical effect of L-dopa upon patients $D$ and $E$, however, encourages the grouping of these subjects with the patients $A$ to $\mathrm{C}$ into a composite group $\mathrm{A}$ to $\mathrm{E}$.

In the Table the CSF HVA and 5-HIAA concentra- tions before treatment and the increase of CSF HVA during L-dopa treatment by the group $A$ to $E$ and by the rest of the patients are compared. The group $A$ to $E$ had pre-treatment HVA and 5-HIAA concentrations not significantly different from those of control subjects, while the other patients with Parkinsonism had much lower concentrations. Also the two groups showed strikingly different relationships between the increase of HVA in the CSF during L-dopa treatment and L-dopa dosage, the regression equations indicating that the efficiency of conversion of L-dopa to CSF HVA was more than five times as great by the group $\mathrm{A}$ to $\mathrm{E}$ than by the other Parkinsonism subjects. The regression equation for the latter group is almost identical with the equation $y=0.0323 x+$ 0.017 previously found (Curzon et al., 1970) for another group of patients with Parkinsonism with low pre-treatment HVA.

After three months' continuous treatment with L-dopa there was no definite improvement in patients $A, B$, and $C$, and only very slight improvement in patients $D$ and $E$. The four patients whose HVA level rose to $<0 \cdot 10 \mu \mathrm{g} / \mathrm{ml}$. were taking L-dopa in a sub-optimal dose $(1.5,1 \cdot 5,1 \cdot 5$, and $2.0 \mathrm{~g}$ daily respectively) at the time of their second lumbar puncture. The dose was subsequently increased gradually and on maximal dosage $(2 \cdot 0,4 \cdot 5$, and $4 \cdot 5 \mathrm{~g}$ daily respectively) three patients showed considerable benefit. In the fourth patient, however, benefit was minimal after three months' treatment at a dose of $2.5 \mathrm{~g}$ daily.

In all other patients the response was maintained after three months' continuous treatment.

Figure 3 shows the changes of CSF 5-HIAA associated with L-dopa treatment. There was little change in most subjects, though there is some suggestion of greater variability at higher L-dopa dosage. 


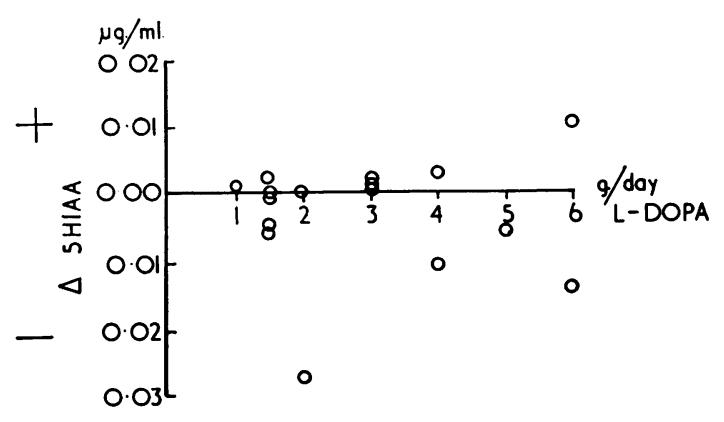

FIG. 3. Effect of L-dopa treatment on 5-HIAA in lumbar CSF.

\section{DISCUSSION}

The low HVA in lumbar CSF found before L-dopa treatment of patients with Parkinsonism is consistent with earlier findings (Bernheimer, Birkmayer, and Hornykiewicz, 1966; Johansson and Roos, 1967; Olsson and Roos, 1968; Curzon et al., 1970). The 5-HIAA content of the CSF was only moderately lower than that of the control group of neurological patients, even when the atypical group $A$ to $E$ was not included. While almost all the HVA in lumbar CSF is derived from the striatum, most of the 5-HIAA present comes from other regions. Therefore, a deficiency in striatal 5-HT metabolism would not necessarily be as clearly reflected in lumbar levels. The 5-HIAA content of lateral ventricular CSF which probably closely reflects striatal 5-HT metabolism has, however, been found to be markedly low in patients with Parkinsonism (Guldberg, Turner, Hanieh, Ashcroft, Crawford, Perry, and Gillingham, 1967).

The group of four patients who showed no more than slight improvement while on L-dopa and only a slight increase of HVA in the CSF may be considered together with cases nos. 6 and 7 previously described (Curzon et al., 1970). The mean CSF HVA of this composite group of six patients while on L-dopa was $0.047 \pm 0.018 \mu \mathrm{g} / \mathrm{ml}$, , which is comparable with the mean HVA value for the untreated control group without Parkinsonism. Thus, HVA in the CSF derived from exogenous L-dopa given to Parkinsonism subjects does not represent an equally effective amount of the intermediate metabolite dopamine as does a similar concentration of HVA in untreated normals. This might be due either to more rapid turnover of dopamine derived from exogenous L-dopa or to a lack of correction of other biochemical abnormalities in Parkinsonism such as defective brain 5-HT synthesis. Another possibility to be considered is that, as decarboxylase required for the conversion of dopa to dopamine is present in many extrastriatal areas, therefore, L-dopa given thera- $z$ peutically might cause the formation of large amounts of dopamine at non-physiological sites? which would probably be ineffective therapeutically However, as the enzymic barrier in the cerebrato capillaries (Owman and Rosengren, 1967) restrictings L-dopa transport into the brain is least effective? specifically in the vicinity of the striatum (Constantin idis, Bartholini, Geissbühler, and Tissot, 1970) exogenous L-dopa penetrates most readily and is converted to dopamine largely in this region? Subjects with the highest HVA increase due too treatment with L-dopa had as a group relatively high HVA levels before treatment. This is consistent with most of the brain dopamine derived from exogenous dopa in these subjects being formed at normal sitess of dopamine synthesis. These findings do not suppor 5 the suggestion (Goodwin, Brodie, Murphy, andBunney, 1970) that the high levels of HVA in thew CSF after L-dopa are largely derived from dopamine? formed and metabolized within the cerebral vasculature.

There is marked association between particularly high HVA formation from L-dopa and the lack $\Phi$ therapeutic effect which is particularly noteworthy subjects $A$ and $B$ as they suffered from akinesia 0 a symptom which often responds to dopa treatmegr? This observation indicates that $\mathbf{L}$-dopa is not merely an anti-Parkinsonism drug which is coincidentafly also a precursor of dopamine and associated metabolites. On the contrary, its failure to alleviai symptoms in patients in whom brain dopamme synthesis is apparently unimpaired indicates that itso therapeutic effect in subjects with low pre-dopa HVA involves effective readjustment of impaired metabolism. The relationship between dopa intake anč increase of CSF HVA for the group A to E appears remarkably linear for a complex biological system $\overrightarrow{\vec{F}}$ It may reflect the control within restricted limits of a 3 rate determining factor for dopamine synthesis in subjects with unimpaired brain dopamine formation:

Results obtained suggest the possibility of using change of HVA content of the CSF upon L-dopat treatment to predict the likelihood of a useful therapeutic outcome. Thus a large increase of HVA 3 . especially when the latter is combined with and atypically high pre-treatment HVA would point to as low likelihood of benefit. Subjects whose HVA rose only to a level comparable to that found in the CSF of subjects without Parkinsonism also would be expected to show little benefit. However, in thesecases increased dosage when practicable could have beneficial effects.

The general lack of significant change of 5-HIAAO levels due to L-dopa treatment is in agreement with a 
previous report (Pullar, Weddel, Hanieh, Ahmed, and Gillingham, 1969). There was, however, some suggestion of greater variability of 5-HIAA at higher dosage which is of interest in view of another study (Van Woert and Bowers, 1970) in which a fall of CSF 5-HIAA was found at dosages between $4.5 \mathrm{~g}$ and $7 \mathrm{~g}$ per day.

We thank the physicians of The National Hospital, Queen Square for permission to study their patients and Dr. J. Gumpert for providing CSF material from control patients. The work was supported by a grant from the Research Advisory Committee of The Institute of Neurology.

\section{REFERENCES}

Bernheimer, H., Birkmayer, W., and Hornykiewicz, O. (1966). Homovanillinsäure im Liquor cerebrospinalis. Untersuchungen beim Parkinson-syndrom und anderen Erkrankungen des ZNS. Wien. klin. Wschr., 78, 417-419.

Calne, D. B., Spiers, A. S. D., Stern, G. M., and Laurence, D. R. (1969). L-dopa in idiopathic Parkinsonism. Lancet, 2, 973-976.

Constantinidis, J., Bartholini, G., Geissbühler, F., and Tissot, R. (1970). La barrière capillaire enzymatique pour la Dopa au niveau de quelques noyaux du tronc cérébral du rat. Experientia (Basel), 26, 381-383.

Cotzias, G. C., Papavasiliou, P. S., and Gellene, R. (1969). Modification of Parkinsonism-chronic treatment with L-dopa. New Engl. J. Med., 280, 337-345.

Curzon, G., Godwin-Austen, R. B., Tomlinson, E. B., and Kantamaneni, B. D. (1970). The cerebrospinal fluid homovanillic acid concentration in patients with Parkinsonism treated with L-dopa. J. Neurol. Neurosurg. Psychiat., 33, 1-6.

Eccleston, D., Ashcroft, G. W., Crawford, T. B. B., Stanton, J. B., Wood, D., and McTurk, P. H. (1970). Effect of tryptophan administration on 5HIAA in cerebrospinal fluid in man. J. Neurol. Neurosurg. Psychiat., 33, 269-272.

Godwin-Austen, R. B., Tomlinson, E. B., Frears, C. C., and Kok, H. W. L. (1969). Effects of L-dopa in Parkinson's disease. Lancet, 2, 165-168.

Goodwin, F. K., Brodie, H. K. H., Murphy, D. L., and Bunney, W. E. (1970). Administration of a peripheral decarboxylase inhibitor with L-dopa to depressed patients. Lancet, 1, 908-911.
Guldberg, H. C., Turner, J. W., Hanieh, A., Ashcroft, G. W., Crawford, T. B. B., Perry, W. L. M., and Gillingham, F. J. (1967). On the occurrence of homovanillic acid and 5-hydroxyindol-3-ylacetic acid in the ventricular C.S.F. of patients suffering from Parkinsonism. Confin. neurol. (Basel), 29, 73-77.

Guldberg, H. C., and Yates, C. M. (1968). Some studies of the effects of chlorpromazine, reserpine and dihydroxyphenylalanine on the concentrations of homovanillic acid, 3,4dihydroxyphenylacetic acid and 5-hydroxy-indol-3-ylacetic acid in ventricular cerebrospinal fluid of the dog using the technique of serial sampling of the cerebrospinal fluid. Brit. J. Pharmac. Chemother., 33, 457-471.

Johansson, B., and Roos, B. E. (1967). 5-hydroxyindoleacetic acid and homovanillic acid levels in the cerebrospinal fluid of healthy volunteers and patients with Parkinson's syndrome. Life Sci., 6, 1449-1454.

Korf, J., and Valkenburgh-Sikkema, T. (1969). Fluorimetric determination of 5-hydroxyindoleacetic acid in human urine and cerebrospinal fluid. Clin. chim. Acta, 26, 301-306.

Mawdsley, C. (1970). Treatment of Parkinsonism with Levodopa. Brit. med. J., 1, 331-337.

Olsson, R., and Roos, B. E. (1968). Concentrations of 5-hydroxyindoleacetic acid and homovanillic acid in the cerebrospinal fluid after treatment with probenecid in patients with Parkinson's disease. Nature (Lond.), 219, 502-503.

Owman, C., and Rosengren, E. (1967). Dopamine formation in brain capillaries-an enzymic blood-brain barrier mechanism. J. Neurochem., 14, 547-550.

Peaston, M. J. T., and Bianchine, J. R. (1970). Metabolic studies and clinical observations during L-dopa treatment of Parkinson's disease. Brit. med.J., 1, 400-403.

Persson, T., and Roos, B. E. (1968). Clinical and pharmacological effects of monoamine precursors or haloperidol in chronic schizophrenia. Nature (Lond.), 217, 854.

Pullar, I. A., Weddel, J. M., Hanieh, A., Ahmed, R., and Gillingham, F. J. (1969). Changes in acid metabolites of dopamine and 5-hydroxytryptamine in lumbar C.S.F. of patients treated with L-dopa. In Abstracts, Second International Meeting of the International Society for Neurochemistry, pp. 328-329. Edited by R. Paoletti, R. Fumagalli, and C. Galli, Tamburini: Milano.

Van Woert, M. H., and Bowers, M. B. (1970). The effect of L-dopa on monoamine metabolites in Parkinson's disease. Experientia (Basel), 26, 161-163.

Weiner, W., Harrison, W., and Klawans, H. (1969). L-dopa and cerebrospinal fluid homovanillic acid in Parkinsonism. Life Sci., 8, Part 1, 971-976.

Yahr, M. D., Duvoisin, R. C., Schear, M. J., Barrett, R. E., and Hoehn, M. M. (1969). Treatment of Parkinsonism with Levodopa. Arch. Neurol. (Chic.), 21, 343-354. 